\title{
A Parametric Malmquist Analysis of Carbon Emission Performance and Its Dynamic Variation in China's Thermal Power Generation
}

\author{
Xiping Wang*, Feng Jiang \\ Department of Economics and Management, North China Electric Power University, \\ 619 Yonghua North Street, Baoding, China
}

Received: 9 April 2017

Accepted: 24 May 2017

\begin{abstract}
This paper employs a parametric Malmquist index to measure carbon emission performance and its dynamic variation of China's thermal power generation sector from 2003 to 2013 . The parametric stochastic frontier analysis (SFA) is applied to estimate the total factor carbon emission performance (TFCP), while the Malmquist carbon emission performance index (MCPI) is used to measure the dynamic change. The main findings are as follows:

1. The average value of TFCP shows an increasing trend but varies among regions. In addition, the investment-based regulations and the efficiency of fuel utilization have positive effects on TFCP, while the effects of R\&D expenditure and fee-based regulations are insignificant.

2. The MCPI of China's provincial thermal power industry grew by an average of $3.1 \%$ annually and was mainly driven by the efficiency change component.

3. According to the average levels of TFCP and MCPI, the 30 provinces are divided into four categories, which provide a scientific basis for policymakers to implement regional-oriented strategies for the improvement of both TFCP and MCPI.
\end{abstract}

Keywords: thermal power generation, carbon emission performance, stochastic frontier analysis, Malmquist index

\section{Introduction}

In response to the challenges arising from global warming and climate change, the Chinese government has made a great effort to control $\mathrm{CO}_{2}$ emissions in terms of both intensity and amount. In 2015 China promised to lower its carbon intensity by $60-65 \%$ by 2030 from the 2005 level and peak its carbon emissions by approximately

*e-mail: hdwxp@126.com
2030. The power industry is of vital importance for the accomplishment of these carbon emission reduction targets. As the largest $\mathrm{CO}_{2}$ emitter among all industries, it consumes approximately $50 \%$ of China's coal and emits more than $40 \%$ of China's $\mathrm{CO}_{2}$ from fossil fuel combustion [1]. Given the coal-dominant energy structure in China, the situation of relying on coal-fired power plants to satisfy the growing demand for electricity can hardly be changed in the near future. Under this circumstance, it is crucial for China's thermal power industry to promote its $\mathrm{CO}_{2}$ emission performance, not only for achieving the 
national carbon emission reduction targets but also for the power industry's low-carbon transition and sustainable development.

In the literature, several indicators have been explored for measuring $\mathrm{CO}_{2}$ emission performance. Among these indicators, carbon productivity [2], carbon intensity [3], and per capita $\mathrm{CO}_{2}$ emissions [4] are particularly attractive and have been successfully applied to many fields. These single-factor efficiency indicators are simple and easy to apply, but they cannot reflect the actual process of $\mathrm{CO}_{2}$ being generated and neglect the influencing factors, such as element substitution, energy mix, and regional economic disparity. In recognition of the limitations of single-factor carbon emission performance, the total factor of carbon emission performance has gained popularity. Under the framework of environmental production technology, Zhou et al. (2010) [5] first proposed the concept of total factor carbon emissions performance (TFCP) by comparing the actual carbon emissions with the carbon emission in the frontier. Also, they constructed the Malmquist $\mathrm{CO}_{2}$ emission performance index (MCPI) by extension the traditional Malmquist productivity index to examine the changes in TFCP over time. Since then, a large number of studies have been devoted to empirically measuring carbon emission performance and its dynamic change at various levels, including the national [6], regional [7-9], and even industrial levels [10-11]. As for the electricity generation sector, Yang and Pollitt (2009) [12] estimate the efficiency of the Chinese coal-fired power plants with data envelopment analysis (DEA) incorporating both undesirable outputs and uncontrollable variables. Related studies also can be found in [13-20].

From a methodological point of view, however, the aforementioned studies mainly adopted non-parametric DEA to measure carbon emission performance. It can easily accommodate both multiple inputs and outputs and does not require a prior assumption regarding the specification of the production function or the distributional form of the error terms. However, the evaluation results from DEA are considered deterministic and do not consider statistical noise. Some studies have used the methods of bootstrap and order-m to overcome the shortcomings of DEA [21-22], while they mainly focused on the static relative efficiency without considering the dynamic efficiency change. Different from DEA, the SFA method, as a parametric approach proposed by Aigner et al. (1997) [23], considers efficiency measures and stochastic noise affecting a frontier. It estimates the frontier production function via a metering method that measures efficiency and considers a variety of environmental factors that influence efficiency. Recently, SFA has also been used to estimate technical efficiency of electricity companies. Chen et al. (2015) [24] examined the technical efficiency of Chinese fossilfuel electricity generation companies from 1999 to 2011. Du et al. (2013) [25] assessed the total factor productivity (TFP) of Chinese fossil-fired power plants. However, these studies are mainly from the perspective of enterprise, while province-level studies using SFA are limited.
In view of this, the main purpose of this study is to measure carbon emission performance and its dynamic variation of China's regional thermal generation from 2003 to 2013 using the parametric Malmquist method.

Compared with the extant studies, the main contributions of this study are as follows. Firstly, it extends the study concerning carbon emission performance by using the SFA method to China's regional thermal power generation. Secondly, this study measures the carbon emission performance of China's regional thermal power generation from both static and dynamic perspectives; specifically, the static TFCP is measured first by the SFA method considering the influential factors on the inefficiency term, and then MCPI is introduced to measure the dynamic variation of carbon emission performance. The decomposition for MCPI is also conducted to evaluate the relative contribution of efficiency change and technology change to the dynamic variation of MCPI. Thirdly, according to the average levels of TFCP and $\mathrm{MCPI}$, the 30 provinces are divided into four categories: high TFCP-low MCPI, low TFCP-low MCPI, low TFCPhigh MCPI, and high TFCP-high MCPI, which can provide a scientific basis for policymakers to implement regional-oriented strategies for the improvement of both TFCP and MCPI.

\section{Material and Methods}

\section{Carbon Emission Performance under the Framework of Environmental Production Technology}

Assuming that there are $\mathrm{n}(\mathrm{n}=1,2, \ldots, \mathrm{N})$ regions and each regional power sector employs capital stock $(\mathrm{K})$, labor force (L), and fossil fuel (F) as inputs to generate electricity (E) as a desirable output and carbon emissions (C) as an undesirable output, this production process can be expressed as:

$S=\{(K, L, F, E, C):(K, L, F)$ can produce $(E, C)\}$

Generally, $S$ is assumed to be a closed and bound set, meaning that finite inputs can only generate finite outputs. According to Zhou et al. (2010) [5], the inputs and desirable outputs are supposed to be strongly or freely disposable. In addition, both the weak disposability assumption and the null-jointness assumption need be considered. This means that the reduction of carbon emissions entails an opportunity cost and the only way to avoid carbon emission is to stop electricity production.

Under the framework of environmental production technology, according to the thoughts of Shephard's distance function, $\mathrm{CO}_{2}$ emission distance function can be defined as 


$$
D_{c}(K, L, F, E, C)=\sup \{\delta:(K, L, F, E, C / \delta) \in S\}
$$

Eq. (2) can be used to define the total factor $\mathrm{CO}_{2}$ emission performance (TFCP) as:

$$
T F C P=1-D_{C}(K, L, F, E, C)
$$

TFCP can explore the $\mathrm{CO}_{2}$ emissions performance of the regional thermal power generation sector from the static perspective. For the purpose of inter-temporal comparisons of the dynamic change in $\mathrm{CO}_{2}$ emissions performance, the Malmquist $\mathrm{CO}_{2}$ emissions performance index (MCPI) can be introduced. Let $t$ and $t+1$ denote two consecutive time periods, following Zhou et al. (2010) [5], the MCPI can be defined as:

$$
\begin{gathered}
\operatorname{MCPI}_{i}(t, t+1)= \\
{\left[\frac{D_{c}^{t}\left(K_{i}^{t+1}, L_{i}^{t+1}, F_{i}^{t+1}, E_{i}^{t+1}, C_{i}^{t+1}\right) \times D_{c}^{t+1}\left(K_{i}^{t+1}, L_{i}^{t+1}, F_{i}^{t+1}, E_{i}^{t+1}, C_{i}^{t+1}\right)}{D_{c}^{t}\left(K_{i}^{t}, L_{i}^{t}, F_{i}^{t}, E_{i}^{t}, C_{i}^{t}\right) \times D_{c}^{t+1}\left(K_{i}^{t}, L_{i}^{t}, F_{i}^{t}, E_{i}^{t}, C_{i}^{t}\right)}\right]^{1 / 2}}
\end{gathered}
$$

Also, MCPI can be decomposed into efficiency change $(\mathrm{EFFCH})$ and technological change (TECH), as shown in Eq. (5):

$$
\begin{aligned}
& \operatorname{MCPI}_{i}(t, t+1)=\frac{D_{c}^{t+1}\left(K_{i}^{t+1}, L_{i}^{t+1}, F_{i}^{t+1}, E_{i}^{t+1}, C_{i}^{t+1}\right)}{D_{c}^{t}\left(K_{i}^{t}, L_{i}^{t}, F_{i}^{t}, E_{i}^{t}, C_{i}^{t}\right)} \\
& \times\left[\frac{D_{c}^{t}\left(K_{i}^{t+1}, L_{i}^{t+1}, F_{i}^{t+1}, E_{i}^{t+1}, C_{i}^{t+1}\right)}{D_{c}^{t+1}\left(K_{i}^{t+1}, L_{i}^{t+1}, F_{i}^{t+1}, E_{i}^{t+1}, C_{i}^{t+1}\right)} \times \frac{D_{c}^{t}\left(K_{i}^{t}, L_{i}^{t}, F_{i}^{t}, E_{i}^{t}, C_{i}^{t}\right)}{D_{c}^{t+1}\left(K_{i}^{t}, L_{i}^{t}, F_{i}^{t}, E_{i}^{t}, C_{i}^{t}\right)}\right]^{1 / 2} \\
& =\operatorname{EFFCH}(t, t+1) \times T E C H(t, t+1)
\end{aligned}
$$

\section{SFA Model Specification}

Estimating the $\mathrm{CO}_{2}$ emission distance function with parametric SFA method needs the assumption on the form of production function. Since the trans-log function is a flexible form and less restrictive than Cobb-Douglas on production and substitution elasticity, we choose the translog production function as follows:

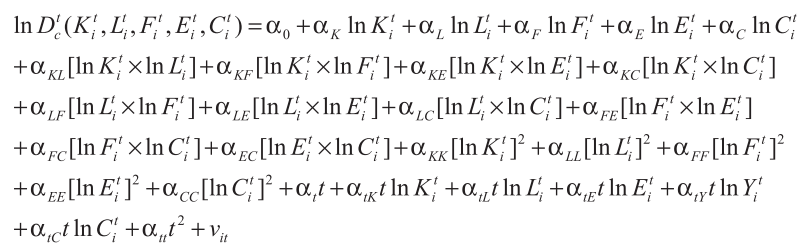

where $v_{i t}$ is a random variable of statistical noise and approximation error. Since the Shephard distance function is linearly homogeneous in carbon, we can get:

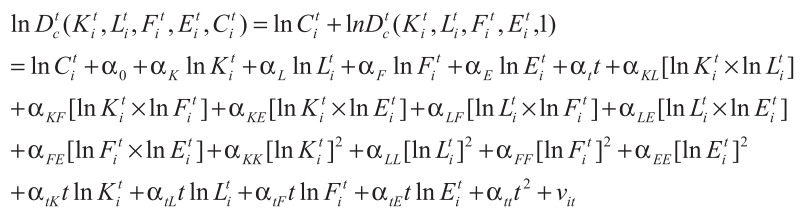

According to Eq. (7), we can obtain:

$$
\begin{aligned}
& D_{c}^{t+1}\left(K_{i}^{t+1}, L_{i}^{t+1}, F_{i}^{t+1}, E_{i}^{t+1}, C_{i}^{t+1}\right) / D_{c}^{t}\left(K_{i}^{t+1}, L_{i}^{t+1}, F_{i}^{t+1}, E_{i}^{t+1}, C_{i}^{t+1}\right) \\
& =\exp \left(\ln D_{c}^{t+1}\left(K_{i}^{t+1}, L_{i}^{t+1}, F_{i}^{t+1}, E_{i}^{t+1}, C_{i}^{t+1}\right)-\ln D_{c}^{t}\left(K_{i}^{t+1}, L_{i}^{+1}, F_{i}^{t+1}, E_{i}^{t+1}, C_{i}^{t+1}\right)\right) \\
& =\exp \left(\alpha_{t}+\alpha_{t K} \ln K_{i}^{t+1}+\alpha_{t L} \ln L_{i}^{t+1}+\alpha_{t F} \ln F_{i}^{t+1}+\alpha_{t E} \ln E_{i}^{t+1}+2 \alpha_{t t}(t+1)\right)
\end{aligned}
$$

$$
\begin{aligned}
& D_{c}^{t+1}\left(K_{i}^{t}, L_{i}^{t}, F_{i}^{t}, E_{i}^{t}, C_{i}^{t}\right) / D_{c}^{t}\left(K_{i}^{t}, L_{i}^{t}, F_{i}^{t}, E_{i}^{t}, C_{i}^{t}\right) \\
& =\exp \left(\ln D_{c}^{t+1}\left(K_{i}^{t}, L_{i}^{t}, F_{i}^{t}, E_{i}^{t}, C_{i}^{t}\right)-\ln D_{c}^{t}\left(K_{i}^{t}, L_{i}^{t}, F_{i}^{t}, E_{i}^{t}, C_{i}^{t}\right)\right) \\
& =\exp \left(\alpha_{t}+\alpha_{t K} \ln K_{i}^{t}+\alpha_{t L} \ln L_{i}^{t}+\alpha_{t F} \ln F_{i}^{t}+\alpha_{t E} \ln E_{i}^{t}+2 \alpha_{t t} t\right)
\end{aligned}
$$

Then technological change (TECH) can be calculated as:

$$
\begin{gathered}
T E C H_{i}(t, t+1)= \\
{\left[\begin{array}{c}
\exp \left(\alpha_{t}+\alpha_{t K} \ln K_{i}^{t+1}+\alpha_{t L} \ln L_{i}^{t+1}+\alpha_{t F} \ln F_{i}^{t+1}+\alpha_{t E} \ln E_{i}^{t+1}+2 \alpha_{t t}(t+1)\right) \\
\times \exp \left(\alpha_{t}+\alpha_{t K} \ln K_{i}^{t}+\alpha_{t L} \ln L_{i}^{t}+\alpha_{t F} \ln F_{i}^{t}+\alpha_{t E} \ln E_{i}^{t}+2 \alpha_{t t} t\right)
\end{array}\right]^{1 / 2}}
\end{gathered}
$$

To calculate efficiency change (EFFCH), re-arranging Eq. (7) we can get:

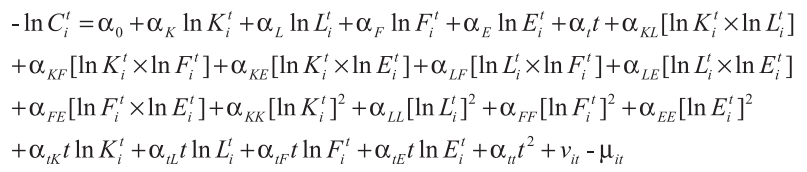

...where $\mu_{i t}=\ln D_{c}^{t}\left(K_{i}^{t}, L_{i}^{t}, F_{i}^{t}, E_{i}^{t}, C_{i}^{t}\right)$ is a non-negative variable representing the inefficiency when $\mathrm{CO}_{2}$ emission performance in $i$ region in the period of $\mathrm{t}$ is evaluated. Based on Eq. (11), carbon emission efficiency (EFF) and its change $(\mathrm{EFFCH})$ can be estimated as:

$$
\begin{gathered}
E F F_{i t}=\exp \left(-\mu_{i t}\right) \\
E E F C H_{i t}(t, t+1)=E F F_{i t+1} / E F F_{i t}
\end{gathered}
$$

It is important to note that the carbon emission efficiency measurements are also affected by other factors. Referring to existing studies [26-28], the efficiency of fuel utilization (FE), the research and development (R\&D) expenditure (RD), the investment-based regulations (IR) and fee-based regulations (FR), are selected as the main influential variables. As a result, it is assumed that the stochastic term $u_{i t}$ is expressed as 


$$
\mu_{i t}=\lambda_{0}+\lambda_{1} F E_{i t}+\lambda_{2} \mathrm{RD}_{i t}+\lambda_{3} I R_{i t}+\lambda_{4} \mathrm{~F} R_{i t}+\omega_{i t}
$$

...where $\lambda_{i}(i=0,1, \ldots, 4)$ represents the vector of unknown parameters to be estimated, here $\lambda_{i}(i=1, \ldots, 4)$ are assumed to be negative; $w_{i t}$ follows truncated normal distribution.

\section{Variables and Data Description}

Panel data of China's 30 provincial (Tibet, Hong Kong, Macao, and Taiwan are not included due to lack of data) thermal power generation sectors over 2003-2013 were collected from China Electric Power Yearbook, China Statistical Yearbook, China Industry Economy Statistical Yearbook, and China Energy Statistical Yearbook. The related variables are illustrated as follows:

1. Input variables. Capital (K) is measured in terms of installed thermal power generating capacity. Labor (L) in power and thermal generation and supply industry is taken as the proxy of the labor in the power generation sector since there are no separate data about it. Data on fuel (F) are collected from the physical quantity sheets balance by region in China Energy Statistical Yearbook and converted into million tons of standard coal equivalent.

2. Output variables. Electricity (E) generated from thermal power plants in each province is used as the single desirable output and $\mathrm{CO}_{2}$ emission (C) is the undesirable output. Because the official data on $\mathrm{CO}_{2}$ emissions from regional thermal power generation are not available in China, they can be obtained as Eq. (14).

$$
\mathrm{CO}_{2}=\sum_{j} \mathrm{CO}_{2}=\sum_{j} F_{j} \times F C U_{j} \times C E F_{j} \times C O F_{j} \times \frac{44}{12}
$$

...where the subscript $j$ represents fuel type, $\mathrm{F}$ denotes the amount of fuel consumption, FCU is the fuel calorific value, CEF stands for carbon emission factor, COF represents the carbon oxidation factor (which is usually assumed to be one for the convenience of calculation), and $44 / 12$ is the conversion factor from carbon to $\mathrm{CO}_{2}$. The descriptive statistics of the input and output variables are shown in Table 1.
3. Influential variables. The efficiency of fuel utilization (FE; in $\mathrm{kWh} / \mathrm{g}$ ) is represented by the reciprocal of the standard coal consumption for unit electricity generation. The R\&D expenditure (RD) is represented by the share of investment R\&D activity of large- and medium-sized industrial enterprises in gross regional production. IR is the investment-based regulations and FR stands for fee-based regulations. They are measured in million RMB and represented by the investment in the treatment of industrial pollution and the fees levied on wastes discharged at the province level, respectively.

\section{Results and Discussion}

\section{Model Estimation Results}

According to the above analysis, we employed Frontier 4.1 to estimate the coefficients of model (11), and the results are shown in Table 2. It can be seen that under a $1 \%$ significance level, the t-ratio of $\gamma$ illustrates that the null hypothesis is rejected and the alternative hypothesis is accepted, which indicates that carbon emission inefficiency does exist and the stochastic frontier analysis is needed. It is also noted that the $\alpha_{\mathrm{E}}$ is negative and statistically significant, which means that the greater amount of electricity generated in region $i$ generally resulted in lower efficiency loss and thus higher performance. For example, Jiangsu as the province with the largest thermal electricity generated also has the highest $\mathrm{CO}_{2}$ emission efficiency, which will be found in the following section. For the four inefficient influential factors, we place them into the model simultaneously. The results are also listed in Table 2.

It can be seen that the coefficients of all four influential factors are negative, meaning that they have positive effects on improving $\mathrm{CO}_{2}$ emission efficiency, which is consistent with the authors' expectation. However, we noticed that only FE and IR are significant at 1\% significance level, while RD and FR are insignificant even at $10 \%$ significance level.

In theory, $R \& D$ plays an important role in combating climate change. More $R \& D$ expenditure can bring the promotion of innovation capability and improvement of environmental efficiency. In our results the RD is insignificant, meaning that the impacts of RD on TFCP

Table 1. Descriptive statistics for inputs and outputs.

\begin{tabular}{|c|c|c|c|c|c|}
\hline Variables & Unit & Mean & Max & Min & Std. dev. \\
\hline Installed capacity & Million KW & $1,962.92$ & 7555 & 88.71 & $1,648.77$ \\
\hline Fuel consumption & Million tons & 28.57 & 147.59 & 1.51 & 28.45 \\
\hline Labor force & Persons & 101,896 & 253,007 & 11,657 & $53,679.144$ \\
\hline Generating capacity & Billion kWh & 975.52 & $4,171.00$ & 44.79 & 823.74 \\
\hline $\mathrm{CO}_{2}$ emissions & Million tons & 91.45 & 390.8 & 4.11 & 74.63 \\
\hline
\end{tabular}


Table 2. Results of estimating the trans-log stochastic production function.

\begin{tabular}{|c|c|c|c|c|c|}
\hline Variables & Coefficient & t-ratio & Variables & Coefficient & t-ratio \\
\hline$\alpha_{0}$ & $3.054^{* *}$ & 2.481 & $\alpha_{\mathrm{tL}}$ & $0.0269^{* *}$ & 2.2509 \\
\hline$\alpha_{\mathrm{K}}$ & $-2.381^{* *}$ & -2.507 & $\alpha_{\mathrm{tK}}$ & $-0.049^{*}$ & -1.652 \\
\hline$\alpha_{L}$ & -0.019 & -0.045 & $\alpha_{\mathrm{tF}}$ & -0.007 & -1.147 \\
\hline$\alpha_{\mathrm{F}}$ & 0.716 & 0.882 & $\alpha_{\mathrm{tE}}$ & 0.044 & 1.463 \\
\hline$\alpha_{\mathrm{E}}$ & $-0.525^{* *}$ & -2.203 & $\alpha_{t}$ & 0.037 & 0.619 \\
\hline$\alpha_{\mathrm{KL}}$ & 0.017 & 0.093 & $\alpha_{\mathrm{tt}}$ & $0.003^{*}$ & 1.696 \\
\hline$\alpha_{\mathrm{KE}}$ & $-0.598^{*}$ & -1.812 & $\lambda_{0}$ & $2.613^{* * *}$ & 4.786 \\
\hline$\alpha_{\mathrm{KF}}$ & 0.019 & 0.205 & $\lambda_{1}$ & $-1.232^{* * *}$ & 5.529 \\
\hline$\alpha_{\mathrm{LE}}$ & 0.131 & 0.803 & $\lambda_{2}$ & -0.909 & -0.922 \\
\hline$\alpha_{\mathrm{LF}}$ & $-0.107^{*}$ & -1.864 & $\lambda_{3}$ & $-0.391^{* * *}$ & -2.736 \\
\hline$\alpha_{\mathrm{EF}}$ & 0.035 & 0.381 & $\lambda_{4}$ & -0.091 & -1.163 \\
\hline$\alpha_{\mathrm{LL}}$ & $-0.097^{*}$ & -1.648 & LR test of the one-sided error & 69.56 & \\
\hline$\alpha_{\mathrm{KK}}$ & $0.411^{* *}$ & 2.115 & sigma-squared & $0.0776^{* * *}$ & 6.742 \\
\hline$\alpha_{\mathrm{FF}}$ & $0.029^{* *}$ & 2.299 & gamma & $0.6998^{* * *}$ & 11.332 \\
\hline$\alpha_{\mathrm{EE}}$ & 0.170 & 1.031 & Log likelihood & 97.64 & \\
\hline
\end{tabular}

Note: $* * * * *$, and $*$ indicate $1 \%, 5 \%$, and $10 \%$ significance levels, respectively.

of China's regional thermal electricity generation are relatively limited. This may be related to the fact that the long-term effects of $\mathrm{RD}$ on $\mathrm{CO}_{2}$ emission efficiency have not been fully revealed. As for fuel efficiency, the coefficient of $\mathrm{FE}$ is negative and significant, indicating that a higher FE will lead to a lower loss of efficiency, and corresponding to a higher $\mathrm{CO}_{2}$ emission performance, which shows that the efficiency of fuel usage is one of the main drivers for $\mathrm{CO}_{2}$ emissions performance. This result is consistent with the findings of Fan et al. (2007) [29]. It should be noted that both IR and FR are the variables standing for environmental regulation. But the coefficient of IR is significant while FR is insignificant. This reveals the complicated effects of regulation on efficiency. The classical theory argues that environmental regulation has a negative effect on efficiency. In contrast, "Porter hypothesis" considers that environmental regulation has positive effects on efficiency. Several studies have empirically investigated the impact of environmental regulation on china's thermal power generation performance [18]. We extend the previous studies by further dividing the market-based regulations into investmentbased regulations and fee-based regulations, and the results partially confirmed the "Porter hypothesis".It needs to be pointed out that currently strengthening the investmentbased regulations may be more effective in reality.

\section{Estimated Results and Discussion of TFCP}

According to the above estimation from the SFA model, we can calculate the value of TFCP of the thermal power generation sector in each province. For comparison, we also estimate the corresponding TFCPs using the DEA model, which describes the maximum possible reduction $\mathrm{CO}_{2}$ emissions while keeping other factors fixed. The results are listed as Fig. 1.

It can be seen that the values of TFCP from DEA are lower than that from SFA, and are more volatile. The reason for this is that the DEA technique regards all deviation from frontier as inefficient, while SFA assumes deviation from efficient frontier including two parts: inefficiency and random shock. Thus, DEA may overestimate the efficiency loss, resulting in the underestimation of the TFCP. To further investigate whether the values of TFCP obtained from SFA are significantly different from that of DEA in a statistical sense, we conduct a Wilcoxon

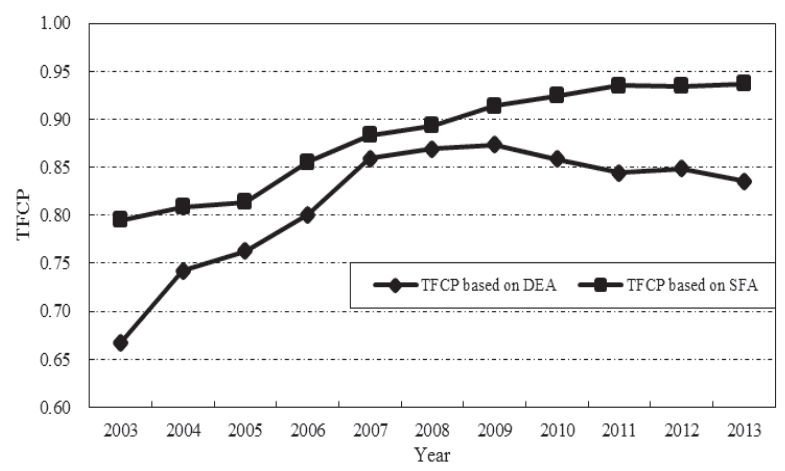

Fig. 1. Comparisons of TFCP. 


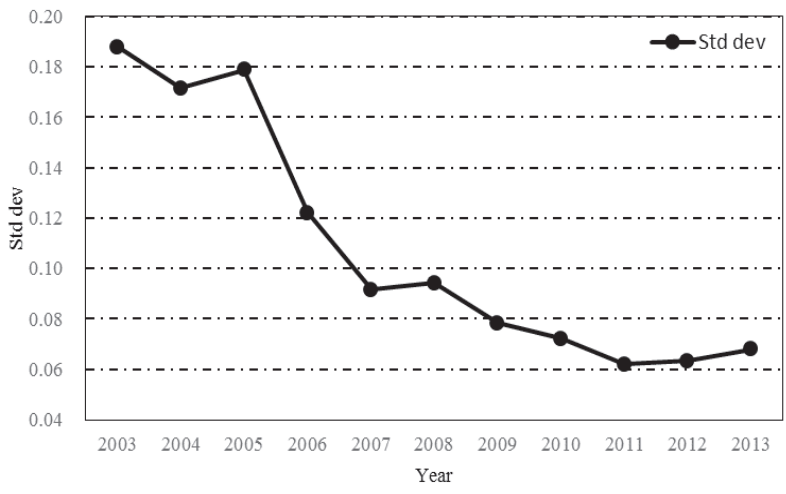

Fig. 2. Changes of the standard deviation of TFCP.

signed-ranks test, and the results indicate that the value of $\mathrm{Z}$ statistic is -2.934 , and the $\mathrm{P}$-value is 0.003 , meaning that the null hypothesis is rejected at $1 \%$ significance level. Thus, the TFCP obtained from SFA should be analyzed further and taken as the basis for measuring MCPI.

In terms of the TFCP obtained from SFA, the average TFCP increased from 0.795 in 2003 to 0.881 in 2013, while regional $\mathrm{CO}_{2}$ emission efficiency is of obvious difference. The average values of TFCP for eastern, central, and western areas $^{1}$ are $0.910,0.905$, and 0.833, respectively, which means that the eastern area has the highest TFCP, followed by central and the western areas with the lowest TFCPs. Furthermore, $\mathrm{CO}_{2}$ emission efficiency scores show great variations across provinces. All eastern provinces except Hainan witnessed higher than 0.90 in terms of TFCP on average. This means that in general the provinces in the eastern area are more efficient than those in other areas, which is the same with the finding of Lam and Shiu (2001) [26]. In order to further investigate the difference of TFCP among provinces, Fig. 2 provides the changes in standard deviation (Std dev) of efficiency values from 2003 to 2013. It can be seen that the difference in TFCP among provinces is significant before 2005 with the standard deviation fluctuating around 0.18 . However, the standard deviation in 2011 is around 0.06 - two times lower than before 2005, meaning that the differences among different regions are gradually being reduced.

\section{Estimated Results and Discussion of MCPI}

Table 3 presents the results of MCPI in China's regional thermal power generation sector, which describes the dynamic change of carbon emission performance.

According to geographical location and economic condition, China's 30 provinces are divided into three areas: the eastern area includes Beijing, Tianjin, Hebei, Liaoning, Shanghai, Jiangsu, Zhejiang, Fujian, Shandong, Guangdong, and Hainan; the central area includes Anhui, Jilin, Heilongjiang, Shanxi, Henan, Hubei, Hunan, and Jiangxi; and the western area includes Shaanxi, Mongolia, Guangxi, Yunnan, Guizhou, Chongqing, Xinjiang, Qinghai, Sichuan, Ningxia, and Gansu.
It can be seen from Table 3 that the average MCPI of the whole sample is 1.031 , indicating that for 30 regions in China as a whole they experienced a $3.1 \%$ improvement in MCPI per year. But this improvement trend is full of great fluctuation, of which the MCPI experienced the highest improvement in 2006. The reason for this is related to the emission reduction policy. It is well known that during the " $11^{\text {th }}$ Five-Year Plan" the Chinese government announced a mandatory target of reducing energy intensity by $20 \%$ by 2010 compared with the 2005 level. Under this target, the thermal power generation sector implemented a range of policy measures, such as "upgrading the large and suspending the small" and promoting large-capacity highefficiency units, as well as implementing the project of replacing coal-fired power plants in big cities with gasfired plants. Under these policies, China has closed down small thermal power plants with total power-generating capacity of 76.83 million kilowatts during the period 2006-2010, accounting for roughly $10.9 \%$ of the total thermal power generation capacity, which makes great contribution to the improvement of MCPI.

Table 3 further presents the two ingredients of MCPI to help identify the contributors to MCPI growth in China's thermal power generation sector. TECH indicates the extent to which MCPI growth is due to the shift in the production frontier over time, hence it represents the capacity of the thermal power industry to improve its production process in an innovative way. It can be found from Table 3 that at the national level the average score of TECH for the whole sample is quite close to unit (1.006), indicating that the annual technological progress in carbon emission reduction is very trivial. EFFCH, on the other hand, reflects the degree to which MCPI growth is caused by the endeavor made by a province's thermal power industry to catch up with a more efficient thermal power sector in other provinces. Table 3 indicates that the average value of EFFCH at the national level is 1.025 , accounting for most of the MCPI growth. Therefore, MCPI growth observed for the thermal power industry during the sample period is almost exclusively driven by efficiency change, while the effect of technological innovation is little.

Table 3 also shows the results of MCPI and its decomposing components for three areas. It can be seen that the similar growth pattern of MCPI in different areas and the value of MCPI of the western area is 1.034, higher than that of eastern and central areas. However the situations at the provincial level are quite different. All provinces except Tianjin, Shanghai, and Chongqing registered a positive shift in MCPI. In order to illustrate the $\mathrm{CO}_{2}$ emission performance and its dynamic change of thermal power generation sector in China's province more clearly, according to the average levels of TFCP and MCPI, we divide the 30 provinces into four basic categories: high TFCP-low MCPI (category 1), low TFCP-low MCPI (category 2), low TFCP-high MCPI (category 3), and high TFCP-high MCPI (category 4), as shown in Fig. 3.

It can be seen from Fig. 3 that most provinces in the eastern area except Hainan and Guangdong are grouped into category 1 . These provinces are leaders in TFCP 
Table 3. MCPI decomposition of SFA results.

\begin{tabular}{|c|c|c|c|c|c|c|c|c|c|c|c|c|}
\hline \multirow{2}{*}{ Year } & \multicolumn{3}{|c|}{ National } & \multicolumn{3}{|c|}{ Eastern area } & \multicolumn{3}{c|}{ Central area } & \multicolumn{3}{c|}{ Western area } \\
\cline { 2 - 15 } & MCPI & EFFCH & TECH & MCPI & EFFCH & TECH & MCPI & EFFCH & TECH & MCPI & EFFCH & TECH \\
\hline 2004 & 1.028 & 1.038 & 0.990 & 1.004 & 1.018 & 0.987 & 1.017 & 1.020 & 0.997 & 1.059 & 1.071 & 0.989 \\
\hline 2005 & 1.002 & 1.008 & 0.993 & 1.007 & 1.017 & 0.990 & 1.026 & 1.026 & 1.001 & 0.978 & 0.988 & 0.991 \\
\hline 2006 & 1.093 & 1.101 & 0.995 & 1.140 & 1.154 & 0.992 & 1.035 & 1.032 & 1.003 & 1.088 & 1.097 & 0.991 \\
\hline 2007 & 1.039 & 1.042 & 0.998 & 1.017 & 1.021 & 0.997 & 1.028 & 1.023 & 1.005 & 1.069 & 1.077 & 0.994 \\
\hline 2008 & 1.012 & 1.011 & 1.000 & 0.999 & 0.997 & 1.002 & 1.017 & 1.011 & 1.006 & 1.021 & 1.026 & 0.995 \\
\hline 2009 & 1.030 & 1.026 & 1.004 & 1.033 & 1.028 & 1.005 & 1.038 & 1.029 & 1.008 & 1.021 & 1.022 & 0.999 \\
\hline 2010 & 1.022 & 1.013 & 1.010 & 1.007 & 0.996 & 1.010 & 1.025 & 1.011 & 1.013 & 1.036 & 1.030 & 1.006 \\
\hline 2011 & 1.034 & 1.013 & 1.021 & 1.020 & 1.001 & 1.019 & 1.028 & 1.004 & 1.024 & 1.052 & 1.031 & 1.020 \\
\hline 2012 & 1.026 & 1.000 & 1.026 & 1.035 & 1.011 & 1.024 & 1.029 & 1.000 & 1.030 & 1.013 & 0.988 & 1.025 \\
\hline 2013 & 1.028 & 1.003 & 1.025 & 1.015 & 0.991 & 1.025 & 1.034 & 1.004 & 1.030 & 1.037 & 1.014 & 1.023 \\
\hline Mean & 1.031 & 1.025 & 1.006 & 1.028 & 1.023 & 1.005 & 1.028 & 1.016 & 1.012 & 1.037 & 1.034 & 1.003 \\
\hline
\end{tabular}

while with relative lower EFFCH, since the TECH is not high enough to compensate for the lower $\mathrm{EFFCH}$, thus leading to MCPI lower than the national average level. These regions should pay more attention to investing more resources in sophisticated equipment, personnel training, and technological innovation for the improvement of their MCPI. On the contrary, category 3 includes the majority of western provinces. These provinces with lower TFCP, due to the catch-up effect, obtained a relatively higher EFFCH, which makes for a great contribution to the improvement of their MCPI. Taking Qinghai as an example, the TFCP of Qinghai is the lowest with an average value of 0.534 , but due to the largest EFFCH of 1.09, so even with the TECH lower than unit, it can also witness the higher MCPI, which provides a typical example to illustrate the contributions of EFFCH to the growth of MCPI.

Different from what was mentioned above, Guangxi, Xinjiang, and Jiangxi are grouped into category 2. They have both lower TFCP and lower MCPI, and these regions should pay attention to not only technological advancement but also management improvement. It should be noted that category 4 includes 4 regions, of which the situation of

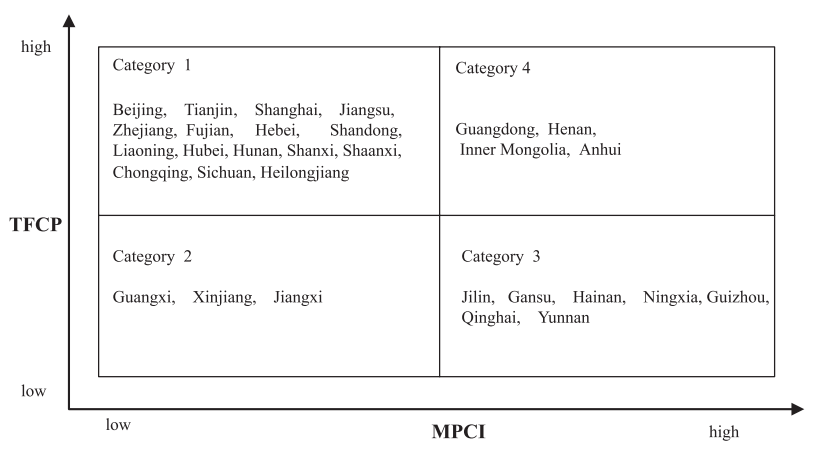

Fig. 3. Categories of provinces based on TFCP and MCPI.
Anhui and Inner Mongolia is similar to category 4. While Guangdong and Henan show different situations, the TFCP of Guangdong ranks fourth, only after Shandong, Jiangsu, and Zhejiang provinces, and also with a relatively lower EFFCH, but the value of TECH is the largest among all provinces, thus the improvement of MCPI is mainly driven from the component of TFCH. Henan shares this common feature with Guangdong.

\section{Conclusions}

A trans-log stochastic frontier analysis method was employed to measure the carbon emission performance in China's thermal power generation industry over the period 2003-2013. On this basis, a carbon emission performance Malmquist index was further applied to measure its dynamic change. The empirical results show that the TFCP of China's thermal power industry has increased as a whole, and some environmental factors such as the efficiency of fuel utilization, investment-based regulations, and so on, have a positive effect on the improvement of TFCP. With regard to the dynamic change of carbon emission performance, the value of MCPI indicates that the carbon emission performance of China's provincial thermal power industry grew by $3.1 \%$ annually, and this was mainly driven by the efficiency change component. The similar growth pattern of MCPI also exists in the eastern, central, and western areas. However, significant difference can be found in MCPI among China's different provinces. These results can have several policy implications.

First, since the growth of MCPI is mainly from the contribution of the EFFCH while the contribution of TECH is minor, improving power generation-related technologies is at the core of promoting $\mathrm{CO}_{2}$ emissions performance of thermal power industry in China. In this regard, the application of coal-fired generating units 
with large-scale, high-efficiency, and low emissions instead of the small ones with poor efficiency and high emissions would be a feasible choice for policymakers. Some clean coal power generation technologies, such as CCS (carbon capture and storage) should be taken as long-term strategies for China's power industry to promote its carbon emission performance [30]. At the same time, it is critical to strengthen $\mathrm{R} \& \mathrm{D}$ for innovating and improving equipment and technology.

Second, considering the differences in carbon emission performance and its dynamic variation among regions, region-specific policies should be put forward by considering local conditions in terms of both technological feasibility and environmental bearing capacity. For provinces with higher TFCP and higher MCPI, policymakers should encourage them to play a leading role continuously. It will be necessary for the provinces with lower TFCP and lower MCPI to change the development mode of "pollute first and treat later". In this regard, better management is very helpful for saving energy and reducing $\mathrm{CO}_{2}$ emissions of thermal electricity generation.

Admittedly, there still exist some limitations in this study. For example, in the SFA model we only consider four variables and do not consider the effects of fuel prices and other factors on $\mathrm{CO}_{2}$ emission inefficiency. In addition, $\mathrm{CO}_{2}$ emissions are measured from the perspective of electricity generation without considering the interregional electricity trade. These limitations will be taken into account in future research.

\section{Acknowledgements}

This work was partially supported by the social science fund of Beijing, China (No. 15JGB050).

\section{References}

1. CHEN Q.X., KANG C.Q., MING H., WANG Z.Y., XIA Q., $\mathrm{XU}, \mathrm{G} . \mathrm{X}$. Assessing the low-carbon effects of inter-regional energy delivery in China's electricity sector. Renewable and Sustainable Energy Reviews 32, 671, 2014.

2. KAYA Y., YOKOBORI K. Environment, Energy and Economy: Strategies for Sustainability. Bookwell PUBLICATIONS, DELHI, 1999.

3. SUN J.W. The decrease of $\mathrm{CO}_{2}$ emission intensity is decarbonization at national and global levels. Energy Policy, 33, 975, 2005.

4. TOLR.S.J., PACALA S.W., SOCOLOW R.H. Understanding long-term energy use and carbon emissions in the USA. Journal of Policy Modeling 31, 425, 2009.

5. ZHOU P., ANG B.W., HAN J.Y. Total factor carbon emission performance: A Malmquist index analysis. Energy Economics, 32, 194, 2010.

6. ZAIM O, TASKIN F. Environmental efficiency in carbon dioxide emissions in the OECD: a non-parametric approach. Journal of Environmental Management 58, 95, 2000.

7. GUO X.D., ZHU L., FAN Y., XIE B.C. Evaluation of potential reductions in carbon emissions in Chinese provinces based on environmental DEA. Energy Policy 39, 2352, 2011.

8. WANG K., YU S.W., ZHANG W. China's regional energy and environmental efficiency: A DEA window analysis based dynamic evaluation. Mathematical and Computer Modelling 58, 1117, 2013.

9. LIN B.Q., DU K.R. Energy and $\mathrm{CO}_{2}$ emissions performance in China's regional economies: Do market-oriented reforms matter? Energy Policy 78,113, 2015.

10. ZHOU G.H., CHUNG W., ZHANG X.L. A study of carbon dioxide emissions performance of China's transport sector. Energy 50, 302, 2013.

11. ZHANG N., ZHOU P., KUNG C.C. Total-factor carbon emission performance of the Chinese transportation industry: A bootstrapped non-radial Malmquist index analysis. Renewable and Sustainable Energy Reviews 41, 584, 2015.

12. YANG H., POLLITT M. Incorporating both undesirable and uncontrollable variables into DEA: the performance of Chinese coal-fired power plants. European Journal of Operational Research 197, 1095, 2009

13. XIE B.C., SHANG L.F., YANG S.B., YI B.W. Dynamic environmental efficiency evaluation of electric power industries: Evidence from OECD and BRIC countries. Energy 74, 147, 2014

14. ZHOU K.L, YANG S.L., SHEN C., DING S. Energy conservation and emission reduction of China's electric power industry. Renewable and Sustainable Energy Reviews 45, 10, 2015.

15. XIE B.C., FAN Y., QU Q.Q. Does generation form influence environmental efficiency performance? An analysis of China's power system. Applied Energy 96, 2611, 2012.

16. ZHANG N., CHOI Y. A comparative study of dynamic changes in $\mathrm{CO}_{2}$ emission performance of fossil fuel power plants in China and Korea. Energy Policy 62, 324, 2013.

17. ZHANG N., ZHOU P., CHOI Y. Energy efficiency, $\mathrm{CO}_{2}$ emission performance and technology gaps in fossil fuel electricity generation in Korea: a meta-frontier non-radial directional distance function analysis. Energy Policy 56, 653, 2013

18. BI G.B., SONG W., ZHOU P., LIANG L. Does environmental regulation affect energy efficiency in China's thermal power electricity generation? Empirical evidence from a slacksbased DEA model. Energy Policy 66, 537, 2014.

19. ZHOU G.H., CHUNG W., ZHANG X.L. Carbon dioxide emissions and energy efficiency analysis of China's regional thermal electricity generation. Journal of Cleaner Production, 83, 173, 2014.

20. WEI C., LOSCHEL A., LIU B. Energy-saving and emission-abatement potential of Chinese coal-fired power enterprises: A non-parametric analysis. Energy Economics 49, 33, 2015.

21. SIMÕES P., MARQUES R., CARVALHO P. Performance assessment of refuse collection services using robust efficiency measures. Resources, Conservation \& Recycling 67 (10), 56, 2012.

22. DUAN N., GUO J.P., XIE B.C. Is there a difference between the energy and $\mathrm{CO}_{2}$ emission performance for China's thermal power industry? A bootstrapped directional distance function approach. Applied Energy 162, 1552, 2016.

23. AIGNER D., LOVELL C., SCHMIDT P. Formulation and estimation of stochastic frontier production function models. Journal of Econometrics 6 (1), 21, 1977.

24. CHEN Z.F., CARLOS P.B., MARIA R.B. A Bayesian stochastic frontier analysis of Chinese fossil-fuel electricity generation companies. Energy Economics 48, 136, 2014. 
25. DU L., HE Y., YAN J. The effects of electricity reforms on productivity and efficiency of China's fossil-fired power plants: an empirical analysis. Energy Economics 40, 804, 2013.

26. LAM P.L., SHIU A. A data envelopment analysis of the efficiency of China's thermal power generation. Utilities Policy 10 (2), 75, 2001.

27. LAM P.L., SHIU A. Efficiency and productivity of China's thermal power generation. Review of Industrial Organization 24 (1), 73, 2004.
28. ZHOU Y., XING X.P., FANG K.N., LIANG D.P., XU C.L. Environmental efficiency analysis of power industry in China based on an entropy SBM model. Energy Policy 57, 68, 2013.

29. FAN Y., LIU L.C., WU G., TSAI HT, WEI Y.M. Changes in carbon intensity in China: empirical findings from 1980-2003. Ecological Economics 62 (3), 683, 2007.

30. WANG X.P., DU L. Study on CCS investment decisionmaking based on real options for China's coal-fired power plants, Journal of Cleaner Production 112, 4123, 2016. 